\title{
Adjuvants in Peripheral Nerve Blocks
}

\author{
Rudra Deshpande ${ }^{1}$, Harshal Wagh ${ }^{2}$, Satish Kulkarni ${ }^{1}$ \\ ${ }^{1}$ Department of Anaesthesia, Lilavati Hospital \& Research Centre, Mumbai, Maharashtra, India. \\ ${ }^{2}$ Department of Anaesthesia, Kokilaben Dhirubhai Ambani Hospital, Mumbai, Maharashtra, India.
}

An increase in the use of peripheral nerve blocks (PNBs) has been noted in recent years. Not only do these blocks provide adequate anaesthesia intraoperatively, but they are also now the cornerstone of perioperative pain management. Superior pain control, a significant decrease in opioid requirements as well as opioid-related side effects, improved patient satisfaction, earlier discharge from hospital and increasing use with the advancement of ultrasound technology have contributed to the increasing use of peripheral nerve blocks [1-4].

Regional anaesthesia techniques including PNBs have also become the need of the hour in recent times of the Covid19 pandemic. As per recent practice recommendations (American Society of Regional Anaesthesia May 2020), Regional anaesthesia is preferred to avoid aerosol-generating procedures associated with General anaesthesia [5].

For postoperative pain management, PNBs are used as a single injection or as a continuous catheter infusion. Single-injection nerve blocks are more commonly done as they are technically easier and quicker. They provide superior analgesia in the immediate postoperative period for various procedures in which the pain intensity is high initially and reduces over significantly over time. Oral analgesics may be effective by then as the effect of PNBs is wearing off gradually over 12 to 24 hours. Rebound pain can however be a significant problem [6]. Continuous catheter techniques are not only technically challenging but require greater monitoring and are prone to secondary block failures due to catheter blockage and displacement [7]. They are labour and resource intensive. Hence the need for adjuvants that will help prolong the duration of PNBs and avoid the placement of continuous catheters has been part of the quest of regional anaesthesiologists. Multiple classes of drugs have been tested as adjuvants in the past. Some have stood the test of time and helped improve the practice of regional anaesthesia while others proved more detrimental. Discussed below are some of the adjuvants that have been successfully used (Table 1).

\section{Opioids}

Opioids are a class of frequently used local anaesthetic adjuncts. Drugs like morphine, fentanyl, sufentanil have been used for years intrathecally as an adjunct $[8,9]$. However, their perineural use in PNBs has not proved as successful $[10,13]$.

Buprenorphine is another drug from the same group that has been used in PNBs as an adjuvant and has been found to increase the duration of sensory blockade significantly $[14,15]$. It is a partial agonist at the Mu Opioid receptor and a Kappa Opioid and Delta Opioid receptor antagonist [16]. It has not received Food and Drug Administration approval for neuraxial or perineural administration. It has been used in the dose of $150-300 \mathrm{mcg}$ [15]. The use of Buprenorphine intravenously or perineurally has been associated with the systemic side effects of Nausea and Vomiting (PONV), sedation and respiratory depression thus limiting its use.

\section{Vasoactive Agents}

One of the most common pharmacological adjuncts used in PNBs is adrenaline. Multiple studies are published on the role of adrenaline as an adjunct using different local anaesthetics [17-20]. It is commonly used in the dose range of $2.5-5 \mathrm{mcg} / \mathrm{ml}$. However, due to the local vasoconstrictor effect, it is seen to prolong the duration of the block slightly [21]. The peak plasma level of local anaesthetic is reduced hence higher local anaesthetic recommended doses. It is more commonly used as a marker of intravascular injection.

Address of Correspondence: Dr. Satish Kulkarni, Consultant, Department of Anaesthesia, Lilavati Hospital \& Research Centre, Mumbai, Maharashtra, India. E-mail: drsatishkulkarni@yahoo.com

DOI: 10.13107/ijra.2021.v02i01.028 | (c) 2021 International Journal of Regional Anaesthesia | Available on www.ijrajournal.com | This is an Open Access article distributed under the terms of the Creative Commons Attribution Non-Commercial License (http://creativecommons.org/licenses/by-nc/3.0) which permits unrestricted non-commercial use, distribution, and reproduction in any medium, provided the original work is properly cited.

How to cite this article: Deshpande R, Wagh H, Kulkarni S | Adjuvants in Peripheral Nerve Blocks | International Journal of Regional Anaesthesia | January-June 2021; 2(1): 63-66. 


\begin{tabular}{|c|c|c|c|}
\hline Drug Name & Classification & Dose & Limitations \\
\hline Buprenorphine [15] & Opioids & $150-300 \mathrm{mcg}$ & $\begin{array}{c}\text { Systemic side effects of PONV, sedation and } \\
\text { respiratory depression }\end{array}$ \\
\hline Adrenaline [18] & Alpha agonist & $2.5-5 \mathrm{mcg} / \mathrm{ml}$ & $\begin{array}{c}\text { Common use as a marker for unintended } \\
\text { intravascular injection }\end{array}$ \\
\hline Clonidine [22] & Alpha 2 agonist & $1-1.5 \mathrm{mcg} / \mathrm{kg}$ & $\begin{array}{c}\text { Higher incidence of cardiovascular side } \\
\text { effects like bradycardia, hypotension. }\end{array}$ \\
\hline Dexmedetomidine [28] & Alpha 2 agonist & $0.5-1 \mathrm{mcg} / \mathrm{kg}$ & Adverse effects like bradycardia and hypotension \\
\hline $\begin{array}{c}\text { Dexamethasone [34, 35] } \\
\text { Ketamine [46] }\end{array}$ & Steroid & $1-8 \mathrm{mg}$ & Steroid-induced hyperglycaemia \\
\hline $\begin{array}{c}\text { Magnesium Sulphate } \\
\text { [50-52] }\end{array}$ & NMDA antagonist & $150-450 \mathrm{mg}$ & Conflicting evidence regarding the effectiveness \\
\hline \multicolumn{4}{|c|}{ Table 1: The adjuvants used successfully } \\
\hline
\end{tabular}

Clonidine is a non-selective imidazole derivative belonging to the alpha-2 adrenoreceptor agonist group. It was used frequently as an adjuvant in PNBs, dose being $1-1.5 \mathrm{mcg} / \mathrm{kg}$. The mechanism of action is thought to be via blockage of hyperpolarization-activated nucleotide-gated channels responsible for cation currents. Clonidine thus maintains A-delta and $\mathrm{C}$ fibres in a hyperpolarised state inhibiting their action potential generation. Another possible action could be localised vasoconstriction via its alpha-1 adrenoreceptor action. Multiple RCTs have evaluated the effect of perineural clonidine and found a motor and sensory block prolonging effect [22-24]. However, clonidine is also associated with cardiovascular side effects of bradycardia, hypotension. This requires greater peri-operative monitoring. A meta-analysis of 14 clinical trials done by El-Boghdadly et al covering 868 patients found that perineural dexmedetomidine had a faster onset of block and longer sensory and motor block duration as compared to perineural clonidine [25]. Hence dexmedetomidine is now preferred over clonidine in PNBs.

Dexmedetomidine belongs to the same class as clonidine. It is eight times more alpha 2 selective than clonidine. It is known to have sedative, analgesic, sympatholytic and anaesthetic sparing properties. Dexmedetomidine provides analgesia via its action at the supraspinal (locus ceruleus) level, spinal level or even at the peripheral adrenoreceptor level by decreasing nociceptive stimulus transmission. It is now being used as an adjunct in peripheral nerve blocks to prolong their duration $[26,27]$. The dose used for PNBs is in the range of $0.5-1 \mathrm{mcg} / \mathrm{kg}[28]$. Neurotoxicity effects of dexmedetomidine were not studied until recently. Xue et al performed neurotoxicity studies on sciatic nerve roots of rats [29]. When they compared the apoptotic changes in the nerve cells between ropivacaine alone and ropivacaine with dexmedetomidine, they found significantly lower apoptosis rates in the dexmedetomidine group. Furthermore, higher doses of dexmedetomidine had lower rates of apoptosis. It has been observed that while low doses prolong block duration significantly, high doses also shorten the onset of block action along with prolonging block duration. Different routes of administration of dexmedetomidine have also been studied. Perineural administration has shown to be more effective and associated with lesser hemodynamic side effects as compared to the intravenous route of administration. Researchers have also compared dexamethasone and dexmedetomidine as adjuvant and found that perineural dexamethasone causes the longest block prolongation with the least amount of side effects $[30,31]$.

\section{Steroids}

Another commonly used adjuvant is dexamethasone. Dexamethasone is a potent long-acting steroid with proven efficacy as an adjuvant in various studies $[32,33]$. It has been studied in various doses ranging from 1 to $8 \mathrm{mg}$, the most common being $8 \mathrm{mg}[34,35]$. Liu et al compared dexamethasone doses of 1 $\mathrm{mg}, 2 \mathrm{mg}$ and $4 \mathrm{mg}$ injected perineurally and found no significant difference in the duration of blockade achieved by either of the three doses [36]. This in the light of neurotoxicity reports in animal models of high dose dexamethasone allows for a significant reduction in the routinely used perineural doses [37]. Steroids are believed to have strong anti-inflammatory and analgesic properties, however, the exact mechanism by which it acts as a PNB adjunct is unknown. They are believed to block transmission of nociceptive $\mathrm{C}$-fibres and suppress ectopic neural discharge [38]. Route of administration is another factor that has been studied and is known to affect the length of block prolongation. Multiple studies have been done on animal models as well as human volunteers/ patients comparing the perineural and intravenous route [39-41]. Most of the studies have documented significantly longer durations of analgesia with perineural drug as compared to a drug given via the systemic route. A meta-analysis done by Zorrilla-Vaca et al noted that when doses in the range of 4- 
$5 \mathrm{mg}$ were used perineurally and intravenously, perineural dexamethasone prolonged the block significantly more [42]. However, when doses of $8 \mathrm{mg}$ or more were used there was no significant difference found in block prolongation.

There is the possibility of post-injection hyperglycaemia even at the doses used in PNB [41-43]. This is particularly disadvantageous in diabetic patients in whom PNBs are frequently used.

A few case reports have been published where a combination of dexamethasone and dexmedetomidine has been used perineurally as an adjuvant. This Dex-Dex combination has shown promising synergistic results with sensory blockade of up to 3-7 days postoperatively and a significant reduction in postoperative opioid consumption. However, the lack of sufficient data on the safety of this combination warrants further investigation and studies $[44,45]$.

\section{Others}

Ketamine is a $\mathrm{N}$-methyl-D-aspartate (NMDA) receptor antagonist that has been studied as an adjuvant to local anaesthetics via the neuraxial route. Very few studies, however, have been done on the use of ketamine as a peripheral nerve block adjuvant and those done have not shown promising results [46].

Midazolam, a commonly used benzodiazepine has been used as an additive in neuraxial anaesthesia techniques and provides analgesia via its gamma-aminobutyric acid (GABA) receptor agonist action [47]. However, it is not an FDA approved additive and use in the peripheral nerve block has mostly been avoided due to neurotoxic effects seen in animal models $[48,49]$.

Magnesium Sulphate is another NMDA receptor antagonist that is being used as an adjuvant in peripheral nerve blocks [50]. It is found to have anti-hypertensive, analgesic and anaesthetic sparing properties when used systemically. Recently its use as an adjuvant to peripheral nerve blocks has been practised. However, there are conflicting reports regarding its effectiveness.

Commercially available solutions are acidic so as to increase water solubility and chemical stability. Alkalinisation of the local anaesthetic solution just before injection by addition of sodium bicarbonate (8.4\%) would increase the amount of non-ionised drug, reduces the pain on injection and onset time of the block. This may be an advantage during infiltration local anaesthesia but does not provide any practical advantage in plexus blocks [53].

\section{Conclusion}

Adjuvants to local anaesthetic agents, whether administered intravenously or perineurally, are a simple and promising alternative to other methods of increasing peripheral nerve block effects. However, none of the currently available adjuvants fulfils all the criteria of an ideal local anaesthetic adjuvant. Dexamethasone and Dexmedetomidine come closest to being a near-ideal option. However, both have associated side effect profiles that restrict their use in specific clinical scenarios. Thus, the search for the ideal adjuvant continues.

\section{References}

1. Hughes MS, Matava MJ, Wright RW, Brophy RH, Smith MV. Interscalene brachial plexus block for arthroscopic shoulder surgery: a systematic review. J Bone Joint Surg Am. 2013;95(14):1318-24.

2. Liu Q, Chelly JE, Williams JP, Gold MS. Impact of peripheral nerve block with low dose local anesthetics on analgesia and functional outcomes following total knee arthroplasty: a retrospectivestudy. Pain Med. 2015;16(5):998-1006.

3. Lenart MJ, Wong K, Gupta RK, Mercaldo ND, Schildcrout JS, Michaels D, et al. The impact of peripheral nerve techniques on hospital stay following major orthopedic surgery. Pain Med.2012;13(6):828-34.

4. Chan EY, Fransen M, Parker DA, Assam PN, Chua N. Femoral nerve blocks for acute postoperative pain after knee replacement surgery. Cochrane Database Syst Rev. 2014;2014(5):Cd009941.

5. Uppal V, Sondekoppam RV, Lobo CA, Kolli S, Kalagara HK. Practice recommendations on neuraxial anesthesia and peripheral nerve blocks during the COVID-19 pandemic. ASRA/ESRA COVID-19 Guidance for Regional Anesthesia March.2020;31.

6. Nobre LV, Cunha GP, Sousa P, Takeda A, Cunha Ferraro LH. [Peripheral nerve block and rebound pain: literature review]. Rev Bras Anestesiol. 2019;69(6):587-93.

7. Ahsan ZS, Carvalho B, Yao J. Incidence of failure of continuous peripheral nerve catheters for postoperative analgesia in upper extremity surgery. J Hand Surg Am. 2014;39(2):324-9.

8. Karaman S, Kocabas S, Uyar M, Hayzaran S, Firat V. The effects of sufentanil or morphine added to hyperbaric bupivacaine in spinal anaesthesia for Caesarean section. EurJAnaesthesiol. 2006;23(4):285-91.

9. Axelsson K, Johanzon E, Essving P, Weckström J, Ekbäck G. Postoperative extradural analgesia with morphine and ropivacaine. A double-blind comparison between placebo and ropivacaine $10 \mathrm{mg} / \mathrm{h}$ or $16 \mathrm{mg} / \mathrm{h}$. Acta Anaesthesiologica Scandinavica.
2005;49(8):1191-9.

10. Flory N, Van-Gessel E, Donald F, Hoffmeyer P, Gamulin Z. Does the addition of morphine to brachial plexus block improve analgesia after shoulder surgery? British Journal of Anaesthesia. 1995;75(1):23-6.

11. Alemanno F, Ghisi D, Fanelli A, Faliva A, Pergolotti B, Bizzarri F, et al. Tramadol and $0.5 \%$ levobupivacaine for single-shot interscalene block: effects on postoperative analgesia in patients undergoing shoulder arthroplasty. Minerva Anestesiol. 2012;78(3):291-6.

12. Kesimci E, Izdes S, Gozdemir M, Kanbak O. Tramadol does not prolong the effect of ropivacaine $7.5 \mathrm{mg} / \mathrm{ml}$ for axillary brachial plexus block. Acta Anaesthesiologica Scandinavica. 2007;51(6):736-41.

13. Fanelli G, Casati A, Magistris L, Berti M, Albertin A, Scarioni M, et al. Fentanyl does not improve the nerve block characteristics of axillary brachial plexus anaesthesia performed with ropivacaine. Acta Anaesthesiol Scand. 2001;45(5):590-4.

14. Jain N, Khare A, Khandelwal S, Mathur P, Singh M, Mathur V. Buprenorphine as an adjuvant to 0.5ङ 37 ; ropivacaine for ultrasound-guided supraclavicular brachial plexus block: A randomized, double-blind, prospective study. Indian Journal of Pain. 2017;31(2):112-8.

15. Tulsyan V, Singh J, Thakur L, Verma V, Minhas A. A comparative study of buprenorphine in two different doses as an adjuvant to levobupivacaine in US-guided lumbar plexus block for postoperative analgesia. Ain-Shams Journal of Anesthesiology. 2021;13(1):7.

16. Virk MS, Arttamangkul S, Birdsong WT, Williams JT. Buprenorphine is a weak partial agonist that inhibits opioid receptor desensitization. J Neurosci. 2009;29(22):7341-8.

17. Schoenmakers KPW, Fenten MGE, Louwerens JW, Scheffer GJ, Stienstra R. The effects of adding epinephrine to ropivacaine for popliteal nerve block on the duration of 
postoperative analgesia: a randomized controlled trial. BMC Anesthesiology. 2015; 15(1):100.

18. Dogru K, Duygulu F, Yildiz K, Kotanoglu MS, Madenoglu H, Boyaci A. Hemodynamic and blockade effects of high/low epinephrine doses during axillary brachial plexus blockade with lidocaine 1.5\%: A randomized, double-blinded study. Reg Anesth PainMed.2003;28(5):401-5.

19. Schoenmakers KP, Vree TB, Jack NT, van den Bemt B, van Limbeek J, Stienstra R. Pharmacokinetics of $450 \mathrm{mg}$ ropivacaine with and without epinephrine for combined femoral and sciatic nerve block in lower extremity surgery. A pilot study. Br J Clin Pharmacol.2013;75(5):1321-7.

20. Weber A, Fournier R, Van Gessel E, Riand N, Gamulin Z. Epinephrine does not prolong the analgesia of $20 \mathrm{~mL}$ ropivacaine $0.5 \%$ or $0.2 \%$ in a femoral three-in-one block. Anesth Analg. 2001;93(5):1327-31.

21. Tschopp C, Tramèr MR, Schneider A, Zaarour M, Elia N. Benefit and Harm of Adding Epinephrine to a Local Anesthetic for Neuraxial and Locoregional Anesthesia: A Meta-analysis of Randomized Controlled Trials With Trial Sequential Analyses. Anesth Analg. 2018;127(1):228-39.

22. Pöpping DM, Elia N, Marret E, Wenk M, Tramèr MR. Clonidine as an adjuvant to local anesthetics for peripheral nerve and plexus blocks: a meta-analysis of randomized trials. Anesthesiology. 2009;111(2):406-15.

23. Chakraborty S, Chakrabarti J, Mandal MC, Hazra A, Das S. Effect of clonidine as adjuvant in bupivacaine-induced supraclavicular brachial plexus block: A randomized controlled trial. Indian JPharmacol.2010;42(2):74-7.

24. McCartney CJL, Duggan E, Apatu E. Should We Add Clonidine to Local Anesthetic for Peripheral Nerve Blockade? A Qualitative Systematic Review of the Literature. Regional Anesthesia \&amp; amp; Pain Medicine. 2007;32(4):330-8.

25. El-Boghdadly K, Brull R, Sehmbi H, Abdallah FW. Perineural Dexmedetomidine Is More Effective Than Clonidine When Added to Local Anesthetic for Supraclavicular Brachial Plexus Block: A Systematic Review and Meta-analysis. Anesth Analg. 2017;124(6):2008-20.

26. Sachdev S, Sharma V, Malawat A, Jethava D, Moin K. Comparison of levobupivacaine alone and levobupivacaine with dexmedetomidine in supraclavicular brachial plexus block: A prospective randomized clinical trial. Indian Journal of Clinical Anaesthesia. 2020;7(1):16-22.

27. Lundblad M, Trifa M, Kaabachi O, Ben Khalifa S, Fekih Hassen A, Engelhardt T, et al. Alpha-2 adrenoceptor agonists as adjuncts to peripheral nerve blocks in children: a meta-analysis. Pediatric Anesthesia. 2016;26(3):232-8.

28. Ray A, Kulkarni S, Kaur K, Paul D, Singh S, Khan S. Comparative study of two different doses of dexmedetomidine as an adjuvant to bupivacaine in the peripheral nerve block. Journal of Marine Medical Society. 2020;22(2):161-5.

29. Xue X, Fan J, Ma X, Liu Y, Han X, Leng Y, et al. Effects of local dexmedetomidine administration on the neurotoxicity of ropivacaine for sciatic nerve block in rats. Mol Med Rep. 2020;22(5):4360-6.

30. Sehmbi H, Brull R, Ceballos KR, Shah UJ, Martin J, Tobias A, et al. Perineural and intravenous dexamethasone and dexmedetomidine: network meta-analysis of adjunctive effects on supraclavicular brachial plexus block. Anaesthesia. 2020. doi: 10.1111/anae.15288. Online ahead of print

31. Albrecht E, Vorobeichik L, Jacot-Guillarmod A, Fournier N, Abdallah FW. Dexamethasone Is Superior to Dexmedetomidine as a Perineural Adjunct for Supraclavicular Brachial Plexus Block: Systematic Review and Indirect Meta-analysis. Anesth Analg. 2019;128(3):543-54.

32. Choi S, Rodseth R, McCartney CJ. Effects of dexamethasone as a local anaesthetic adjuvant for brachial plexus block: a systematic review and meta-analysis of randomized trials.BrJAnaesth. 2014;112(3):427-39.

33. Pehora C, Pearson AM, Kaushal A, Crawford MW, Johnston B. Dexamethasone as an adjuvant to peripheral nerve block. Cochrane Database Syst Rev. 2017;11(11):Cd011770.

34. Marhofer P, Columb M, Hopkins PM, Greher M, Marhofer D, Bienzle M, et al. Dexamethasone as an adjuvant for peripheral nerve blockade: a randomised, tripleblinded crossover study in volunteers. BrJAnaesth. 2019;122(4):525-31.

35. Golwala $M$, Swadia V, Dhimar AA, Sridhar N. Pain relief by dexamethasone as an adjuvant to local anaesthetics in supraclavicular brachial plexus block. J Anaesth Clin Pharmacol. 2009;25(3):285-8.

36. Liu J, Richman KA, Grodofsky SR, Bhatt S, Huffman GR, Kelly IV JD, et al. Is there a dose response of dexamethasone as adjuvant for supraclavicular brachial plexus nerve block? A prospective randomized double-blinded clinical study. Journal of clinical anesthesia. 2015;27(3):237-42.

37. Williams BA, Hough KA, Tsui BY, Ibinson JW, Gold MS, Gebhart G. Neurotoxicity of adjuvants used in perineural anesthesia and analgesia in comparison with ropivacaine. Regional Anesthesia \& Pain Medicine. 2011;36(3):225-30--30.

38. Attardi B, Takimoto K, Gealy R, Severns C, Levitan E. Glucocorticoid induced upregulation of a pituitary $\mathrm{K}+$ channel $m R N A$ in vitro and in vivo. Receptors \& channels. 1993;1(4):287-93.

39. Chong MA, Berbenetz NM, Lin C, Singh S. Perineural versus intravenous dexamethasone as an adjuvant for peripheral nerve blocks: a systematic review and meta-analysis. Regional Anesthesia \& Pain Medicine. 2017;42(3):319-26.

40. Zhao $W-L, O u X-F, L i u J$, Zhang $W$-S. Perineural versus intravenous dexamethasone as an adjuvant in regional anesthesia: a systematic review and meta-analysis. Journal of Pain Research. 2017;10:1529-43.

41. Desmet M, Braems H, Reynvoet M, Plasschaert S, Van Cauwelaert J, Pottel H, et al. $I V$ and perineural dexamethasone are equivalent in increasing the analgesic duration of a single-shot interscalene block with ropivacaine for shoulder surgery: a prospective, randomized, placebo-controlled study. British journal of anaesthesia. 2013;111(3):445-52.

42. Zorrilla-Vaca A, Li J. Dexamethasone Injected Perineurally is More Effective than Administered Intravenously for Peripheral Nerve Blocks. The Clinical journal of pain. 2018;34(3):276-84.

43. Tien M, Gan T, Dhakal I, White W, Olufolabi A, Fink R, et al. The effect of anti-emetic doses of dexamethasone on postoperative blood glucose levels in non-diabetic and diabetic patients: a prospective randomised controlled study. Anaesthesia. 2016;71(9):1037-43.

44. Kassem H, Urits I, Viswanath O, Kaye AD, Eskander JP. Use of Dexmedetomidine With Dexamethasone for Extended Pain Relief in Adductor Canal/Popliteal Nerve Block During Achilles Tendon Repair. Cureus. 2020;12(12):e11917-e.

45. Zusman RP, Urits I, Kaye AD, Viswanath O, Eskander J. Synergistic Effect of Perineural Dexamethasone and Dexmedetomidine (Dex-Dex) in Extending the Analgesic Duration of Pectoral Type I and II Blocks. Cureus. 2020;12(9):e10703-e.

46. Lee IO, Kim WK, Kong MH, Lee MK, Kim NS, Choi YS, et al. No enhancement of sensory and motor blockade by ketamine added to ropivacaine interscalene brachial plexus blockade. Acta Anaesthesiol Scand.2002;46(7):821-6.

47. Nishiyama T, Matsukawa T, Hanaoka K. Continuous epidural administration of midazolam and bupivacaine for postoperative analgesia. Acta Anaesthesiol Scand. 1999;43(5):568-72.

48. Malinovsky JM, Cozian A, Lepage JY, Mussini JM, Pinaud M, Souron R. Ketamine and midazolam neurotoxicity in the rabbit. Anesthesiology. 1991;75(1):91-7.

49. Demirel E, Ugur HC, Dolgun H, Kahilogullari G, Sargon ME, Egemen N, et al. The neurotoxic effects of intrathecal midazolam and neostigmine in rabbits. Anaesth Intensive Care. 2006;34(2):218-23.

50. Mukherjee K, Das A, Basunia SR, Dutta S, Mandal P, Mukherjee A. Evaluation of Magnesium as an adjuvant in Ropivacaine-induced supraclavicular brachial plexus block: A prospective, double-blinded randomized controlled study. J Res Pharm Pract. 2014;3(4):123-9.

51. Jebali C, Kahloul M, Hassine NI, Jaouadi MA, Ferhi F, Naija W, et al. Magnesium Sulfate as Adjuvant in Prehospital Femoral Nerve Block for a Patient with Diaphysial Femoral Fracture: A Randomized Controlled Trial. Pain Research and Management. 2018;2018:2926404.https://doi.org/10.1155/2018/2926404

52. Hung Y-C, Chen C-Y, Lirk P, Wang C-F, Cheng J-K, Chen C-C, et al. Magnesium Sulfate Diminishes the Effects of Amide Local Anesthetics in Rat Sciatic-Nerve Block. RegAnesth Pain Med.2007;32(4):288-295.

53. Kerry Brandis. Alkalinisation of local anaesthetic solutions. Australian Prescriber Vol34/Number6/December 2011. 